\title{
The Thrombogram in Rare Inhenited Coagulation Disorders: Its Relation to Clinical Bleeding
}

\author{
Raed AI Dieri ${ }^{1}$, Flora Peyvandi ${ }^{2}$, Elena Santagostino ${ }^{2}$, Muriel Giansily ${ }^{3}$, \\ Pier Mannucc io Mannuc $\mathrm{i}^{2}$, J ean Franç o is Schved ${ }^{3}$, Suzette Béguin ${ }^{1}$, \\ H. Coenraad Hemker ${ }^{1}$
}

${ }^{1}$ Synapse Laboratory, Card iovasc ular Research Institute (CARIM), University of Maastric ht, The Netherlands; ${ }^{2}$ Angelo Bianchi Bonomi Hemophilia and Thrombosis Center, IRC CS Maggiore Hospital and University of Mila no, Italy; ${ }^{3}$ Laboratoire Central d'Hema tologie, Centre Hospita lier Universita ire, Montpellier, France

\section{Keywords}

Thrombogram, clotting factors, thrombin

\section{Summary}

We investigated the relation between clotting factor concentration, the parameters of the thrombin generation curve (the thrombogram) and the severity of clinically observed bleeding in patients with congenital deficiency of prothrombin $(\mathrm{n}=21)$, factor $\mathrm{V}(\mathrm{n}=22)$, factor VII $(n=22)$, factor $X(n=10)$, factor XI $(n=7)$ and factor XII $(n=6)$. The parameters used were: area under the curve (endogenous thrombin potential, ETP), peak concentration of thrombin attained and lag time before manifest formation.

Peak height and ETP varied linearly with the concentration of prothrombin. For the other factors these parameters hyperbolically approached to the $100 \%$ limit with increasing clotting factor concentration. Half normal ETP was seen at about the following concentrations: prothrombin $(50 \%)$, factor V $(1 \%)$, factor VII $(2 \%)$, factor X $(5 \%)$ and factor XI (1\%). As a rule, the peak height was somewhat more sensitive to clotting factor decrease than the ETP was.

In all the patients with severe bleeding symptoms the ETP was less than $20 \%$ of normal. Bleeding tendency was absent or mild in patients with an ETP of $30 \%$ or higher. This value (except for prothrombin) is already obtained at concentrations of clotting factor of $1 \%-2 \%$, which corroborates the clinical observation that a severe bleeding tendency is only seen in severe clotting factor deficiencies (less than 1\%). The one exception was a patient with factor VII deficiency and severe bleeding, who showed a normal ETP value, albeit with a decreased peak height and a prolonged lag-time.

\section{Introduction}

It is well known from clinical experience that in patients with rare inherited deficiencies of coagulation factors the relation between the outcome of coagulation screening tests (prothrombin time and activated partial thromboplastin time), the plasma levels of deficient factors and

Correspondence to: Prof. H. Coenraad Hemker, Cardiovascular Research Institute (CARIM), Synapse BV, P.O. Box 616, 6200 MD, University of Maastricht, The Netherlands - Tel.: +31-43-3881674, Fax: +31-43-3884159; E-mail: HC.Hemker@thrombin.com the bleeding tendency can vary markedly from deficiency to deficiency and from patient to patient (1). Hence, the measurement of factor levels with conventional functional assays is often of little value to predict the bleeding tendency in clinical practice. The thrombin generation curve (the thrombogram) reflects the function of the ensemble of plasmatic pro- and anticoagulant factors and is characterized by three main parameters: a) the lag time, which is for all practical purposes equivalent to the clotting time; b) the peak height, which represents the maximal velocity of net thrombin production and that, when antithrombin is in the normal range, reflects the maximal prothrombinase activity attained and c) the endogenous thrombin potential (ETP). The latter is the area under the thrombin generation curve and represents the total amount of substrate that can potentially be converted by thrombin if enough substrate is available. In this study the possibility that a measurement of overall coagulation function such as the thrombogram may be used as an indicator of the bleeding tendency in rare coagulation factor deficiencies has been evaluated. The properties of the thrombogram were correlated with the levels of clotting factors and the occurrence and severity of bleeding symptoms in a series of well characterized cases of inherited deficiencies of fibrinogen and factors (F) II, V, VII, X, XI, XII, XIII (1).

\section{Patients, Materials and Methods}

Patients

We used samples from patients with rare inherited coagulation deficiencies referred to or diagnosed in Montpellier (17 cases of FVII deficiency) or in Milan (all the remaining cases of fibrinogen, FII, V, VII, X, XI, XII or XIII deficiency). General characteristics of these patients and the spectrum of their bleeding symptoms have been published (2-5). To establish the type and severity of bleeding symptoms, patients and carriers were interviewed with a specially tailored questionnaire devised to collect focused and objective information (2-5). For the purpose of this study, severe bleeders were defined as those with a history of spontaneous limb- or life-threatening hemorrhages, such as a hemarthroses, muscle hematomas, umbilical cord, gastrointestinal and central nervous system bleeding. Mild bleeders were defined as those who bled only after trauma or surgery or had minor symptoms such as epistaxis and menorrhagia. Non bleeders were those who were asymptomatic. The diagnosis of the original referring centers from Europe and the Middle East were confirmed in Milan and Montpellier on plasma samples received frozen in dry ice. Both patients and asymptomatic obligatory carriers of the various defects (who usually had factor plasma levels at about half the normal levels) were included in the study. Analysis of some of the mutations underlying these defects has been published (6-11). 
Table 1 The correlation of the ETP with the coagulant activity of prothrombin in patients and relatives. The thrombogram was determined in the extrinsic and intrinsic system

\begin{tabular}{|c|c|c|c|c|c|}
\hline \multirow{2}{*}{$\begin{array}{c}\text { Code } \\
\text { FII }(n=21)\end{array}$} & \multirow{2}{*}{ FII: C\% } & \multirow[t]{2}{*}{ FII: Ag\% } & \multicolumn{2}{|c|}{ ETP (\% of Normal) } & \multirow{2}{*}{\begin{tabular}{|c} 
Bleeding \\
Symptoms
\end{tabular}} \\
\hline & & & Extrinsic & Intrinsic & \\
\hline 1 & 1 & 10 & $<5$ & $<5$ & Severe \\
\hline 2 & 4 & 4 & $<5$ & $<5$ & Severe \\
\hline 3 & 4 & 5 & 7 & 7 & Severe \\
\hline 4 & 7 & 15 & 15 & 10 & Severe \\
\hline 5 & 7 & 6 & 18 & 16 & Severe \\
\hline 6 & 8 & 8 & 15 & 15 & Severe \\
\hline 7 & 8 & 9 & 15 & 15 & Severe \\
\hline 8 & 9 & 14 & 19 & 20 & Mild \\
\hline 9 & 10 & 8 & 15 & 17 & Mild \\
\hline 10 & 26 & 19 & 20 & 26 & None \\
\hline 11 & 39 & 53 & 59 & 53 & None \\
\hline 12 & 44 & 45 & 45 & 39 & None \\
\hline 13 & 44 & 45 & 52 & 49 & None \\
\hline 14 & 51 & 53 & 54 & 58 & None \\
\hline 15 & 51 & 58 & 53 & 55 & None \\
\hline 16 & 57 & 50 & 58 & 53 & None \\
\hline 17 & 58 & 48 & 51 & 52 & None \\
\hline 18 & 60 & 56 & 60 & 57 & None \\
\hline 19 & 64 & 47 & 65 & 59 & None \\
\hline 20 & 70 & 74 & 76 & 67 & None \\
\hline 21 & 85 & 86 & 89 & 90 & None \\
\hline
\end{tabular}

Plasma

Patient samples were obtained by collecting blood on $1 / 10$ vol $0.13 \mathrm{M}$ trisodium citrate and centrifugation at $2900 \mathrm{~g}$ for $15 \mathrm{~min}$. As a reference, plasma from at least 40 apparently healthy men and women not pregnant and not taking oral contraceptives was pooled and a final centrifugation was done at $4^{\circ} \mathrm{C}$, for one hour at $23000 \mathrm{~g}$. The reference plasma was arbitrarily given a value of $100 \%$ and was stored at $-80^{\circ} \mathrm{C}$. In order to minimize contact activation, hydrophobic material (propylene tubes and pipettes) was used throughout.

\section{Chemical, Reagents and Buffers}

Chromogenic substrates used for thrombin determination were S-2238 (H-D-ph-pip-arg-pNA, Chromogenix AB, Malmö, Sweden) and the slow
Table 2 The correlation of the ETP with the coagulant activity of factor $\mathrm{V}$ and the bleeding symptoms in patients and relatives. The thrombogram was determined in the extrinsic and intrinsic system

\begin{tabular}{|c|c|c|c|c|c|}
\hline \multirow{2}{*}{$\begin{array}{c}\text { Code } \\
\text { FV }(n=22)\end{array}$} & \multirow[t]{2}{*}{ FV: C\% } & \multirow[t]{2}{*}{ FV: Ag\% } & \multicolumn{2}{|c|}{ ETP (\% of Normal) } & \multirow{2}{*}{$\begin{array}{c}\text { Bleeding } \\
\text { Symptoms }\end{array}$} \\
\hline & & & Extrinsic & Intrinsic & \\
\hline 1 & $<1$ & 0.1 & 0 & 0 & Severe \\
\hline 2 & $<1$ & $<1$ & 0 & 0 & Severe \\
\hline 3 & $<1$ & $<1$ & 0 & 0 & Severe \\
\hline 4 & $<1$ & 0.2 & $<20$ & $<20$ & Severe \\
\hline 5 & $<1$ & 0.1 & $<5$ & $<5$ & Severe \\
\hline 6 & $<1$ & 0.1 & $<10$ & $<10$ & Severe \\
\hline 7 & 2 & 0.5 & 100 & 100 & Mild \\
\hline 8 & 2 & 1 & 90 & 87 & Mild \\
\hline 9 & 4 & 6 & 79 & 77 & Mild \\
\hline 10 & 4 & 2.3 & 100 & 96 & None \\
\hline 11 & 6 & 3 & 88 & 78 & None \\
\hline 12 & 33 & 37 & 100 & 100 & None \\
\hline 13 & 37 & 45 & 100 & 96 & None \\
\hline 14 & 48 & 44 & 100 & 97 & None \\
\hline 15 & 48 & 100 & 84 & 80 & None \\
\hline 16 & 52 & 38 & 100 & 100 & None \\
\hline 17 & 54 & 64 & 100 & 96 & None \\
\hline 18 & 57 & 70 & 100 & 98 & None \\
\hline 19 & 64 & 62 & 100 & 92 & None \\
\hline 20 & 69 & 69 & 82 & 72 & None \\
\hline 21 & 72 & 53 & 100 & 100 & None \\
\hline 22 & 95 & 136 & 100 & 95 & None \\
\hline
\end{tabular}

reacting substrates SQ68 (MZ-Aib-Arg-pNA, Serbio Laboratories, Asniéres, France) or Msc-Val-Arg- PNA and DEMZ-Gly-Arg-pNA synthesized by Rijkers et al. (12). Recombinant relipidated human tissue factor (rTF), polybrene and calcium free, was a gift from Dade Behring (Marburg-Germany). Dade ${ }^{\circledR}$ Actin ${ }^{\circledR}$ FS, a suspension of purified soy phosphatides in an ellagic acid solution (concentrations unknown), was obtained from Dade Behring (Germany). Phospholipids were added in the form of vesicles consisting of 20 mole-\% phosphatidyl serine (PS) and 80 mole- $\%$ phosphatidyl choline (PC), prepared as previously described (13) (Avanti Polar Lipids Inc., Alabama, USA). Bovine serum albumin (BSA), lot A-7030, was from Sigma Chemicals (St. Louis, USA). Ancrod, the fibrinogen-clotting enzyme extracted from the Malayan Pit Viper was the commercial preparation $\operatorname{Arvin}{ }^{\circledR}$ (Knoll AG, Ludwigshafen, Germany). At the final concentration used (1 U/ml plasma,
Table 3 The relationship between the coagulant activity of factor VII, the parameters of the thrombogram and the bleeding symptoms in factor VII deficiency. The thrombogram was determined in the extrinsic system. n. a.: not available

\begin{tabular}{|c|c|c|c|c|c|c|c|}
\hline $\begin{array}{c}\text { Code } \\
\text { FVII }(n=22)\end{array}$ & FVII: C\% & FVII: $\mathbf{A g} \%$ & \begin{tabular}{|c|} 
Lag-time \\
Ratio
\end{tabular} & $\begin{array}{c}\text { Peak time } \\
\text { Min }\end{array}$ & $\begin{array}{c}\text { Peak height } \\
\text { (\% of Normal) }\end{array}$ & \begin{tabular}{|c|} 
ETP \\
(\% of Normal)
\end{tabular} & $\begin{array}{c}\text { Bleeding } \\
\text { Symptoms }\end{array}$ \\
\hline 1 & $<1$ & n.a. & 6 & 6 & 36 & 100 & Mild \\
\hline 2 & $<1$ & 52 & 23 & 11 & 29 & 31 & Mild \\
\hline 3 & $<1$ & 8 & 11.8 & 8.6 & 29 & 75 & Mild \\
\hline 4 & $<1$ & 65 & - & - & 0 & 0 & Severe \\
\hline 5 & 1.5 & 2 & 5 & 6.0 & 31 & 90 & Mild \\
\hline 6 & 2 & 62 & 3.2 & 3.4 & 53 & $>100$ & Mild \\
\hline 7 & 2 & n.a. & 1.2 & 2.3 & 71 & 80 & Mild \\
\hline 8 & 2 & n.a. & 1.5 & 2.9 & 63 & $>100$ & Mild \\
\hline 9 & 2 & 7 & 4.4 & 4.5 & 43 & 100 & Severe \\
\hline 10 & 2 & 2 & 4.5 & 3 & 11 & 48 & Mild \\
\hline 11 & 3 & 37 & 5 & 3.7 & 45 & 63 & None \\
\hline 12 & 3 & 23 & 2.2 & 2.8 & 44 & 95 & Mild \\
\hline 13 & 3 & 10 & 3.75 & 2.7 & 128 & 100 & None \\
\hline 14 & 6 & 48 & 1.5 & 1.6 & 80 & 84 & Mild \\
\hline 15 & 6 & 76 & 1.5 & 1.7 & 58 & $>100$ & Mild \\
\hline 16 & 6 & 6 & 1.6 & 2 & 100 & 100 & None \\
\hline 17 & 7 & 25 & 1.5 & 2 & 68 & 73 & None \\
\hline 18 & 8 & n.a. & 3 & 2.5 & 71 & 100 & None \\
\hline 19 & 9 & 55 & 1.5 & 2.7 & 16 & 80 & None \\
\hline 20 & 14 & n.a. & 1.25 & 2 & 52 & 95 & None \\
\hline 21 & 28 & 75 & 1.25 & 2 & 80 & 100 & None \\
\hline 22 & 51 & 45 & 1 & 1.5 & 150 & 100 & None \\
\hline
\end{tabular}



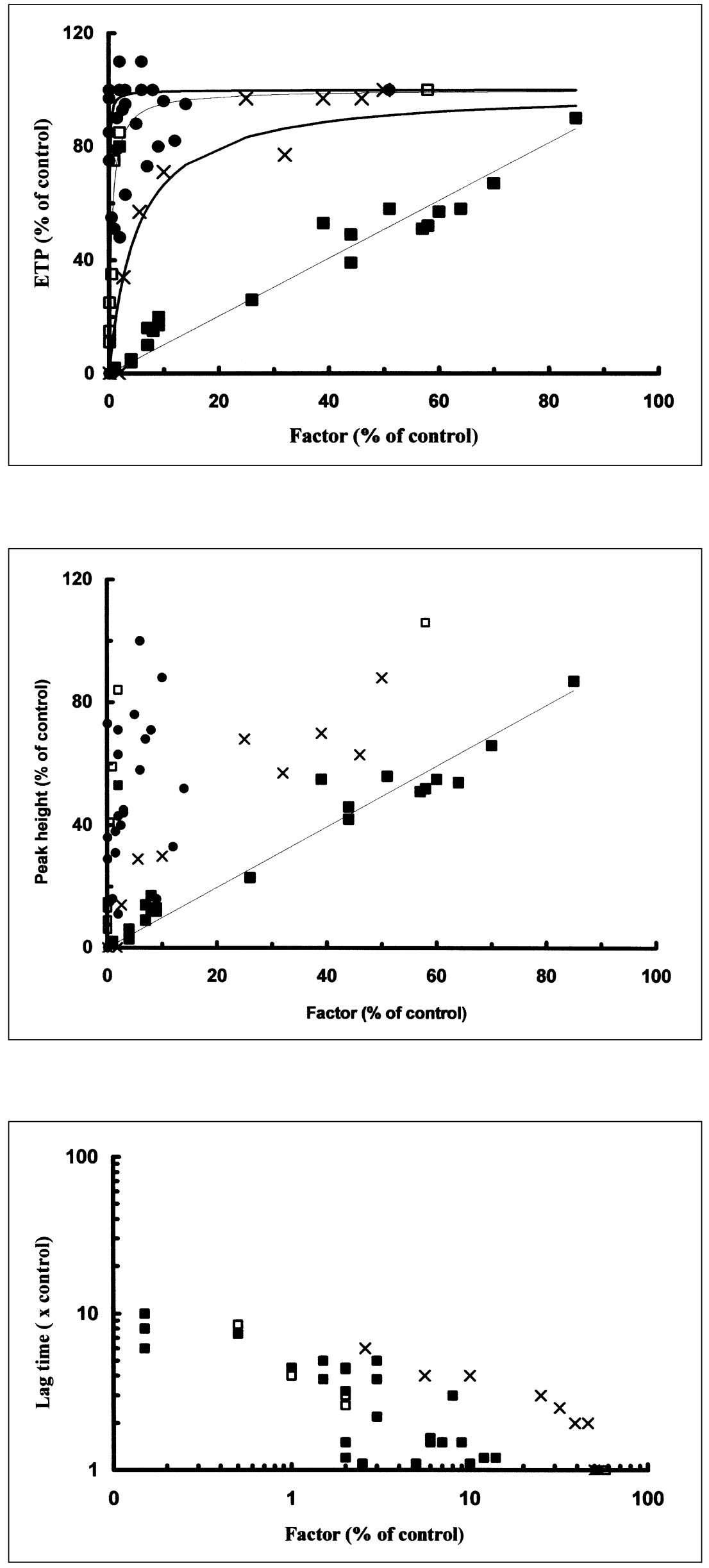

Fig. 1 The ETP as a function of clotting factor concentration, $(\square)$ : prothrombin, $(\times)$ : factor $X,(\square)$ : factor V, $(\mathbf{)})$ : factor VII. Lines: best fitting; hyperbola (factors V, VII and X) or straight line (prothrombin)
Fig. 2 The peak height as a function of clotting factor concentration $(\square)$ : prothrombin, $(\times)$ : factor $X,(\square)$ : factor $\mathrm{V},(\mathbf{O})$ : factor $\mathrm{VII}$
Fig. 3 The lag-time as a function of clotting factor concentration $(\log )$. ( $\square$ ): factor VII, $(\times)$ : factor $X,(\square)$ : factor $\mathrm{V}$ 


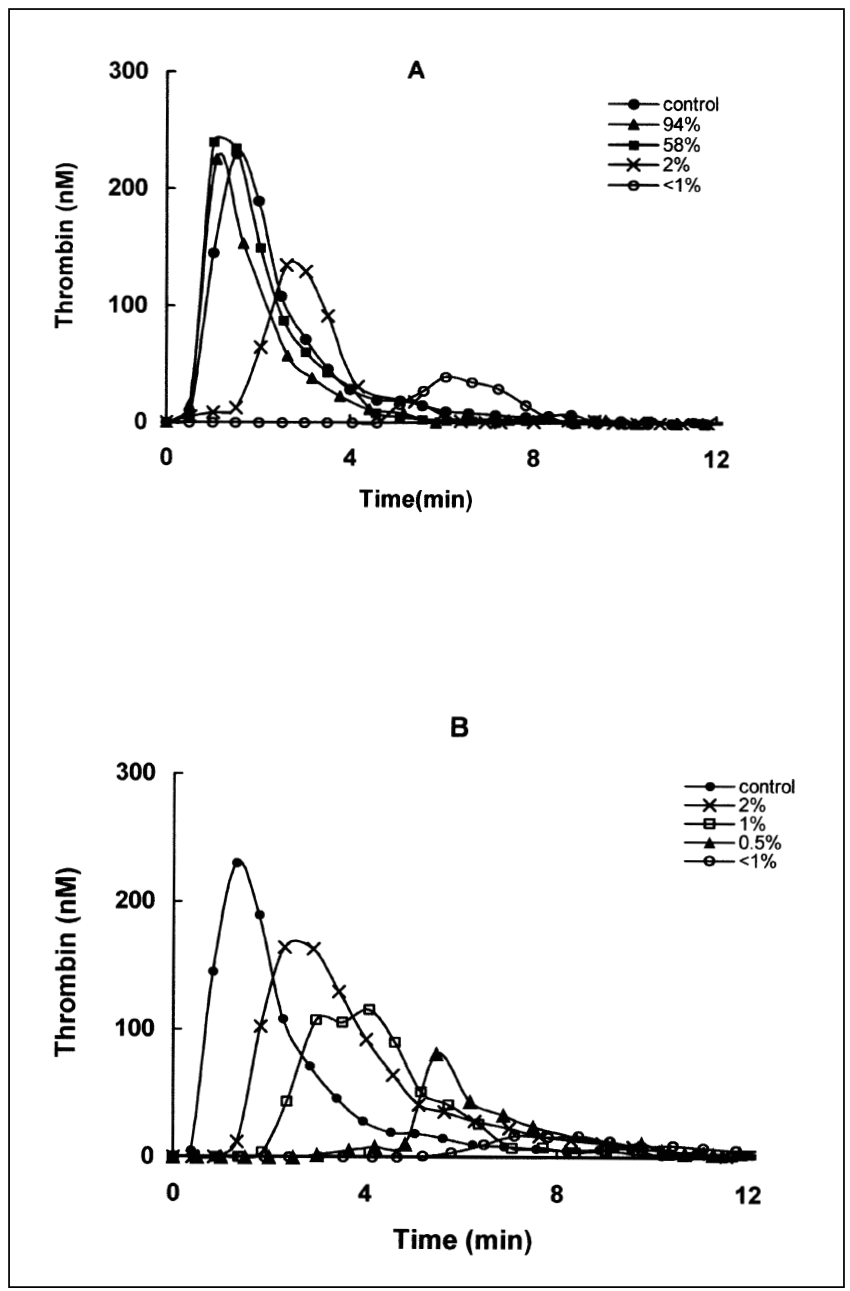

Fig. 4 The TF-induced thrombograms in factor $\mathrm{V}$ deficiency. A; patient plasmas, B; severe deficiency spiked with different amounts (\%) of normal plasma

causing a clotting time of 50-60 s) Ancrod did not activate platelets or any clotting factor, notably FV and FVIII. Staphylocoagulase was prepared as described earlier (14). Buffer A pH 7.35 consists of 0.02 M Hepes, $0.15 \mathrm{M}$ $\mathrm{NaCl}, 0.5 \mathrm{~g} / \mathrm{l} \mathrm{BSA}$. Buffer B is buffer A with 0.02 M EDTA adjusted to $\mathrm{pH}$ 7.9.

\section{Defibrination of Plasma}

At $37^{\circ} \mathrm{C}, 20 \mu \mathrm{l}$ of a $50 \mathrm{U} / \mathrm{ml}$ Ancrod solution was added per milliliter of platelet-poor plasma (PPP). After $10 \mathrm{~min}$ at $37^{\circ} \mathrm{C}$ and $10 \mathrm{~min}$ incubation on ice the fibrin clot was wounded out on a plastic spatula.

\section{Thrombin Generation: the Thrombogram}

Thrombin formed was assessed by a subsampling method (SM) or by monitoring optical density (OD) of the pNA released from a slow reacting chromogenic thrombin substrate added to plasma (15-17). In both methods, the reaction mixture for the measurement of thrombin generation consisted of four parts of plasma and one part of buffer A containing phospholipid vesicles and activator. These were incubated for at least $5 \mathrm{~min}$ at $37^{\circ} \mathrm{C}$ before one part of $\mathrm{CaCl}_{2} 0.1 \mathrm{M}$ was added to start the reaction. The activators used were: $\mathrm{a}$ : for the extrinsic system: $4 \mu \mathrm{M}$ phospholipid with $15 \mathrm{pM}$ rTF; b: for the intrinsic system, $4 \mu \mathrm{M}$ phospholipid and 1/6 volume of Actin ${ }^{\circledR} \mathrm{FS}$.

Alternatively, in the subsampling method kaolin $(50 \mu \mathrm{g} / \mathrm{ml}$ final $)$ was used as the contact activator. $240 \mu \mathrm{l}$ of plasma was used in $360 \mu \mathrm{l}$ final volume. From the reaction mixture $10 \mu \mathrm{l}$ aliquots were transferred at regular intervals (10-60 s) into cuvettes containing $490 \mu \mathrm{l} \mathrm{S}-2238,0.2 \mathrm{mM}$ in buffer B. After approximately $2 \mathrm{~min}$ or at the time when visible color production could be observed, the reaction was stopped by $1 \mathrm{M}$ citric acid solution. Sampling time and stopping time were registered through push buttons on the pipettes, connected to a personal computer. From these times and the measured OD $(405 \mathrm{~nm})$, the amidolytic activity $(\mathrm{OD} / \mathrm{min})$ is automatically calculated and converted into equivalent thrombin concentrations via a standard curve constructed with active site titrated thrombin.

In the OD-monitoring method, the slow reacting thrombin substrate ( $0.5 \mathrm{mM}$ final concentration) was added together with the $\mathrm{CaCl}_{2}$ solution that starts the reaction. The kinetic constants of the substrate are such that the velocity of product formation is proportional to thrombin concentration during the course of the reaction. The course of product formation over time is monitored optically in a laboratory automation (Cobas Fara Centrifugal Analyzer). The first derivative of this curve gives the course of amidolytic activity. The amidolytic activity measured is related to thrombin concentration via a standard curve made with active site titrated thrombin.

\section{Handling of the Data}

The course of the amidolytic activity in time is essentially the same for both methods. Amidolytic activity is due to thrombin and to the $\alpha_{2}$ macroglobulinthrombin $\left(\alpha_{2} \mathrm{M}-\mathrm{T}\right)$ complex formed during the reaction. The amidolytic activity curve can be dissected into the free thrombin curve and the $\left(\alpha_{2} \mathrm{M}-\mathrm{T}\right)$ complex curve by mathematical means (16). From the thrombin-time curve three parameters were obtained: the lag-time required for forming $10 \mathrm{nM}$ thrombin, the area under the curve [endogenous thrombin potential (ETP)] and the peak height.

\section{Factor Assay Methods}

The Milan and Montpellier laboratories used one-stage functional assays based upon the prothrombin time or the partial thromboplastin time and commercial plasma made deficient of any given clotting factor by immunoadsorption. Fibrinogen was measured by the Clauss method based upon the fibrin polymerization time using bovine thrombin (Laboratoire Stago, Asnières, France).

\section{Measurement of Residual Prothrombin in Serum}

After thrombin generation was over, the remaining ("serum") sample was put on ice and stored at $-80^{\circ} \mathrm{C}$. Residual prothrombin was measured using staphylocoagulase as described (14). The amount of prothrombin consumed was expressed in \% of the initial amount of plasma prothrombin.

\section{Results}

\section{Normal Values}

We used OD-monitored thrombograms from 118 normal plasmas to determine the normal course of extrinsically triggered thrombin generation. Thrombograms in the extrinsic system were also determined in 10 patients with afibrinogenaemia (less than $5 \mathrm{mg} / \mathrm{dL}$ ) and in 21 patients with complete FXIII deficiency (subunit A). All these patients were severe bleeders. Because defibrination is part of the experimental procedure, no difference from normals can be expected in these cases. We therefore chose to use these plasmas as controls for the other rare coagulation defects, reasoning that venipuncture, shipping and storage were comparable in the patient samples but differed from the conditions applied to the 118 normal individuals. In fresh normal plasma the ETP was $385 \pm 50 \mathrm{nM}$.min in the extrinsic system and $415 \pm 40$ intrinsically (rounded figures from Wielders et al. (18). The ETP in the frozen samples from fibrinogen and FXIII deficient patients was $339 \pm 50$ nM.min extrinsically and $380 \pm 58$ nM.min in the intrinsic system, i.e. resp. $88 \pm 13 \%$ and $92 \pm 19 \%$ of that in fresh plasmas. 


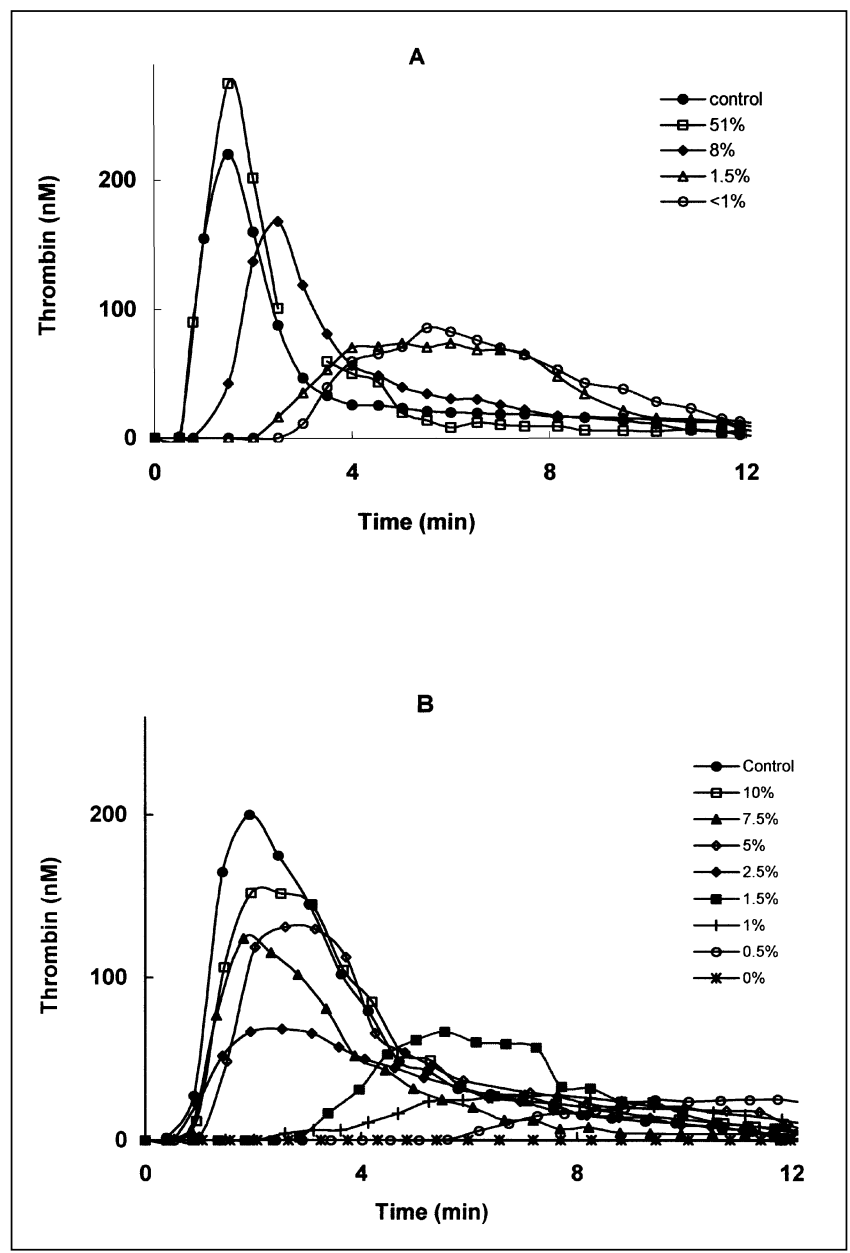

Fig. 5 The TF-induced thrombograms in factor VII deficiency. A; patient plasmas, B; FVII-depleted plasma spiked with different amounts (\%) of normal plasma

\section{Prothrombin Deficiency}

In 21 individuals whose prothrombin activity varied between $1 \%$ and $85 \%$ of normal, the relationship between the levels of prothrombin and the ETP was measured using the OD-monitoring method. Pro-

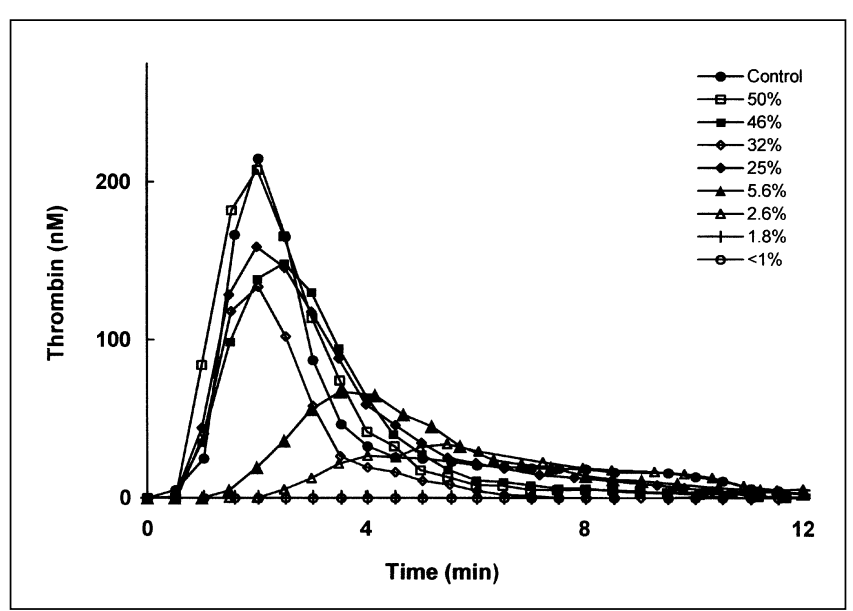

Fig. 6 The TF-induced thrombograms in patient plasmas of factor $\mathrm{X}$ deficiency $(<1 \%$ to $50 \%$ of normal) thrombin activity was linearly correlated to the ETP $\left(r^{2}=0.94\right)$ (Fig. 1). No difference was observed between the ETP measured in the intrinsic and in the extrinsic system (Table 1). There was a small and inconsistent variation in the lag time of the TF-induced and contact activation-induced curves (data not shown).

\section{Factor V Deficiency}

Thrombin generation was measured in plasmas from 22 individuals with levels of FV activity between less than $1 \%$ and $95 \%$ using the OD-monitoring method in the intrinsic and extrinsic systems. No difference in the ETP was found between the two systems (Table 2). Both ETP and peak height reached near normal values at FV levels of approximately $2 \%$ (Table 2 and Fig. 1, 2). The lag times became prolonged with decreasing FV concentration but showed large variations (Fig. 3). Clinical data indicated that only patients with FV levels of lower than $2 \%$ had a severe bleeding tendency (Table 2).

In a selected group of patients, including four in whom FV was undetectable (below 1\%) we also measured thrombin generation with the subsampling method. Fig. 4a shows that at a FV level of $2 \%$ and below, the lag-time was prolonged and the peak height of the thrombogram and the ETP were markedly reduced. This correlates with the clinical history, because patients with levels of $2 \%$ or higher did not bleed unless after severe challenge by trauma or major surgery.

We also spiked the plasma from a severe FV deficient patient (below $1 \%$ ) with increasing amounts of normal plasma (0.5\%-2\%) and then measured TF-induced thrombin generation via the subsampling method (Fig. 4b). The results were comparable with those obtained for the patients: half normal thrombin generation was seen at between $1 \%$ and $2 \%$ of added FV. Only in the more severe deficiencies (below 2\%) the level of residual prothrombin exceeded the $5-10 \%$ found in normal reference plasma.

\section{Factor VII Deficiency}

Twenty-two individuals were studied with FVII levels ranging between $<1 \%$ and $51 \%$. Fig. 5 and Table 3 show the results. Thrombin formation, that in normal plasma starts immediately, is retarded in FVII-deficient plasmas as the functional activity of FVII plummets below $2 \%$. Patients with FVII levels of $2 \%$ or higher did not bleed or bled only after severe challenge by trauma or surgery (Table 3 ). In the cases with less than $2 \%$ of this factor, the time to peak was delayed and the peak height was remarkably diminished but the area under the curve (ETP) was essentially normal (Fig. 5a). The same picture was seen in experiments in which a FVII depleted plasma (less than 1\%) was supplemented with increasing concentrations of normal PPP (Fig. 5b).

\section{Factor X Deficiency}

Ten individuals were studied with FX deficiency between less than $1 \%$ and $50 \%$ of normal. Fig. 6 and Table 4 show that when the functional activity of FX was below 10\%, the parameters of the thrombogram lag-time and peak were markedly abnormal. The ETP was almost similar in the extrinsic and intrinsic systems. Again the ETP values did correlate with the clinical picture, because patients with FX levels below $10 \%$ had abnormal ETP values and were severe bleeders, with symptoms appearing spontaneously or after trivial trauma. In patients with a FX activity between $10 \%$ and $50 \%$ only the lag-time of thrombin generation and the peak were abnormal but the ETP remained within 
Table 4 The relationship between the coagulant activity of factor $\mathrm{X}$, the parameters of the thrombogram and the bleeding symptoms in factor $\mathrm{X}$ deficiency. n. a.: not available

\begin{tabular}{|c|c|c|c|c|c|c|c|c|}
\hline $\begin{array}{c}\text { Code } \\
\text { FX (n= 10) }\end{array}$ & FX: C\% & FX: Ag\% & $\begin{array}{c}\text { Lag-time } \\
\text { Ratio }\end{array}$ & $\begin{array}{c}\text { Peak time } \\
\text { Min }\end{array}$ & $\begin{array}{c}\text { Peak height } \\
\text { (\% of Normal) }\end{array}$ & $\begin{array}{c}\text { ETP (\% of Normal) } \\
\text { Extrinsic }\end{array}$ & $\begin{array}{c}\text { Bleeding } \\
\text { Intrinsic }\end{array}$ & \begin{tabular}{c} 
Symptoms \\
\hline 1
\end{tabular} \\
\hline & $<1$ & 15 & - & - & - & 0 & 0 & Severe \\
2 & 2 & 11 & - & - & - & 0 & 0 & Severe \\
3 & 3 & 59 & 6 & 5 & 14 & 38 & 30 & Mild \\
4 & 6 & 7 & 4 & 3.5 & 29 & 59 & 55 & Mild \\
5 & 10 & n.a. & 4 & 4 & 30 & 72 & 70 & Mild \\
6 & 25 & 58 & 3 & 2 & 68 & 100 & 95 & None \\
7 & 32 & n.a. & 2.5 & 2 & 57 & 80 & 75 & None \\
8 & 39 & 45 & 2 & 2 & 70 & 95 & 90 & None \\
9 & 46 & 49 & 2 & 2.5 & 63 & 95 & 100 & None \\
10 & 50 & 52 & 1 & 2 & 88 & 100 & 100 & None \\
\hline
\end{tabular}

the normal limits. These patients had no bleeding tendency even after trauma. This suggests that the threshold range of $\mathrm{FX}$ required to obtain normal thrombin generation is approximately $10 \%$ of normal.

\section{Factor XI Deficiency}

Seven individuals with FXI deficiency ( $<1 \%$ to $54 \%$ ) were studied. In agreement with the results of Keularts et al. (19) the extrinsic thrombogram was normal in all cases at rTF concentration of $15 \mathrm{pM}$. The thrombogram in the intrinsic system was inhibited by $55-65 \%$ in patients with FXI $<1 \%$ (Fig. 7). The patients were mild bleeders only at levels of FXI below 1\%, all the remaining levels being associated with no bleeding symptom.

\section{Factor XII Deficiency}

Six asymptomatic individuals with various degrees of FXII deficiency were studied ( $<1 \%$ to $53 \%$ ). Thrombin generation was indistinguishable from normal in the extrinsic system. Thrombin generation in the intrinsic system was normal when as little as $1 \%$ FXII was present but no thrombin was generated within 30 minutes at FXII levels below $1 \%$.

\section{Disc ussion}

It is a well known problem in clinical hematology that neither the prothrombin time, nor the activated partial thromboplastin time, nor the level of the individual clotting factors can accurately predict the presence and severity of a bleeding tendency. Assuming that the course of thrombin activity in clotting plasma (the thrombogram) is a more comprehensive and global function test of the clotting system (20), we investigated in this study whether or not the bleeding tendency of patients with congenital deficiencies of the factors II, V, VII, X, XI and XII is indeed correlated with features of the thrombogram. We chose to divide the patients in three groups according to their bleeding tendency, defined as severe, mild or absent.

We observed that, in general, with decreasing clotting factor concentration, the lag time of thrombin generation did or did not lengthen depending upon which factor is lacking. With decreasing clotting factor concentrations the peak amount of thrombin as a rule diminishes before the ETP begins to decrease. With exception of one case of FVII deficiency (Table 3), all patients who showed a severe bleeding tendency had an ETP of less than $20 \%$ of normal. There were important quantitative differences between the individual clotting factors. In prothrombin deficiency the ETP as well as the peak amount of thrombin were linearly proportional to the plasma level of prothrombin but no significant prolongation of the lag phase was seen. This indicates that a small decrease in prothrombin directly causes a proportional change in peak and ETP. All the other clotting factors had to decrease to a considerable extent before the features of the thrombogram were affected. The concentration of factor X that caused the ETP to decrease by $50 \%$ was approximately $5 \%$ (Fig. 2). Factors V, VII and XI showed a half normal ETP at 1\%, $2 \%$ and $1 \%$ respectively. For a further discussion on the effect in FXI deficient patients of tissue factor concentration and platelets on thrombin generation, see Keularts et al. (19). In patients with severe factor XII deficiency (below 1\%) the thrombogram was clearly abnormal in the intrinsic system but normal in the extrinsic system, as expected.

The general picture that stems from these observations is that only a small percentage of the normal amount of clotting factors suffices to obtain normal prothrombin conversion. This is in agreement with biochemical experiments indicating that the actual amount of prothrombin converting enzymes formed in clotting plasma is less than $10 \mathrm{nM}(22)$ whereas the plasma levels of FV $(25 \mathrm{nM})$ and FX $(100 \mathrm{nM})$ are in significant excess [see also Butenas et al. (23)]. Independently of the clotting factor involved, we observed that there was no bleeding tendency in those patients with an ETP greater than 20\%, whereas all patients with an ETP below $20 \%$ had bled. This is consistent with the previously observed correlation between bleeding and the level of oral anticoagulation and the ETP (20). In orally anticoagulated patients the incidence of bleeding increases sharply at INR levels greater than 3.5 (21), which correspond to ETP values of below $17 \%$ of normal (20).

From these results it appears that the risk of severe bleeding due to abnormalities in the plasmatic coagulation system is invariably accompanied by an aberrant thrombogram. The data presented here together with those from the investigation in patients on oral anti-

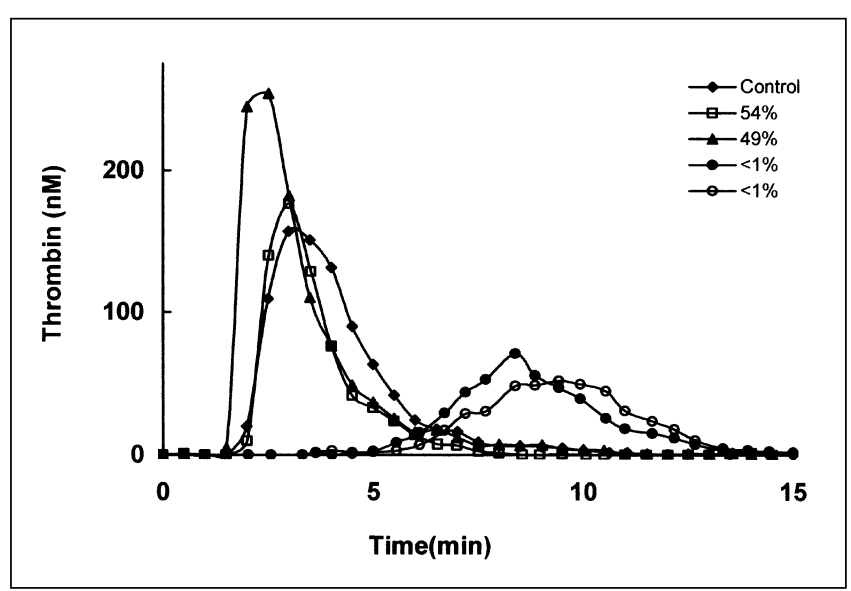

Fig. 7 The intrinsic-induced thrombograms in patient plasmas of factor XI deficiency ( $<1 \%$ to $54 \%$ of normal) 
coagulants (20), indicate that a bleeding tendency becomes manifest as soon as the ETP drops under a value of $20 \%$.

Consequently, in patients who present with a bleeding syndrome, the finding of an abnormally low thrombogram in PPP strongly suggests that a defect in the plasmatic clotting factors exists and a further analysis of the clotting factors pattern is required.

Our hypothesis is that the clotting factor levels in plasmatic deficiencies eventually determine the amount of thrombin formed and that, with otherwise normal fibrinogen, vessel wall and platelets, thrombin formation determines the hemostatic response. If this is correct, the thrombogram should differentiate between bleeding tendencies even if they occur at otherwise equally low concentrations of the deficient factor. This type of information is impossible to obtain in the rare bleeding disorders described here because it would require to examine a sufficiently large number of patients with identically low levels of the deficient factor but different hemostatic responses to a comparable hemostatic challenge.

In conclusion, the hemorrhagic diathesis that ensues from congenital deficiencies in the plasmatic thrombin generation system is sensed by the thrombogram carried out in defibrinated, platelet poor plasma. Superposed modulations of the bleeding tendency due to variations in fibrinogen, platelets, vessel wall and the fibrinolytic system are evidently not reflected in the presented embodiment of this test. They might be more fully sensed in tests that allow measurement in platelet rich plasma.

\section{References}

1. Peyvandi F, Mannucci PM. Rare coagulation disorders. Thromb Haemost 1999; 82: 1207-14.

2. Peyvandi, F, Mannucci PM, Asti D, Abdoullahi M, Di Rocco N, Sharifian R. Clinical manifestations in 28 Italian patients with severe factor VII deficiency. Hemophilia 1997; 3: 242-6.

3. Lak M, Sharifian R, Peyvandi F, Mannucci PM. Symptoms of inherited factor V deficiency in 35 Iranian patients. Br J Haematol 1998; 103: 1067-9.

4. Peyvandi F, Mannucci PM, Lak M, Abdoullahi M, Zeinali S, Sharifian R, Perry D. Congenital factor X deficiency: spectrum of bleeding symptoms in 32 Iranian patients. Br J Haematol 1998; 102: 626-8.

5. Lak M, Keihani M, Elahi F, Peyvandi F, Mannucci PM. Bleeding and thrombosis in 55 patients with inherited afibrinogenaemia. Br J Haematol 1999; 107: 204-6.

6. Duga S, Asselta R, Santagostino E, Zeinali S, Simonic T, Malcovati M, Mannucci PM, Tenchini ML. Missense mutations in the human beta fibrinogen gene cause congenital afibrinogenemia by impairing fibrinogen secretion. Blood 2000; 95: 1336-41.

7. Peyvandi F, Jenkins PV, Mannucci PM, Billio A, Zeinali S, Perkins SJ, Perry DJ. Molecular characterisation and three-dimensional structural analysis of mutations in 21 unrelated families with inherited factor VII deficiency. Thromb Haemost 2000; 84: 250-7.
8. Akhavan S, Mannucci PM, Lak M, Mancuso G, Mazzucconi MG, Rocino, A, Jenkins PV, Perkins SJ. Identification and three-dimensional structural analysis of nine novel mutations in patients with prothrombin deficiency. Thromb Haemost 2000; 84: 989-97.

9. Montefusco MC, Duga S, Asselta R, Santagostino E, Mancuso G, Malcovati M, Mannucci PM, Tenchini ML. A novel two base pair deletion in the factor $\mathrm{V}$ gene associated with severe factor $\mathrm{V}$ deficiency. Br J Haematol 2000; 111: 1240-6.

10. van Wijk R, Montefusco MC, Duga S, Asselta R, van Solinge W, Malcovati M, Tenchini ML, Mannucci PM. Coexistence of a novel homozygous nonsense mutation in exon 13 of the factor $\mathrm{V}$ gene with the homozygous Leiden mutation in two unrelated patients with severe factor $\mathrm{V}$ deficiency. Br J Haematol 2001; 114: 871-4.

11. Peyvandi F, Carew JA, Perry DJ, Hunault M, Khanduri U, Perkins SJ, Mannucci PM, Bauer KA. Abnormal secretion and function of recombinant human factor VII as the result of modification to a calcium binding site caused by a 15-base pair insertion in the F7 gene. Blood 2001; 97: 960-5.

12. Rijkers DT, Wielders SJ, Tesser GI, Hemker HC. Design and synthesis of thrombin substrates with modified kinetic parameters. Thromb Res 1995; 79: 491-9.

13. Rosing J, Tans G, Govers-Riemslag JW, Zwaal RF, Hemker HC. The role of phospholipids and factor $\mathrm{Va}$ in the prothrombinase complex. J Biol Chem 1980; 255: 274-83.

14. Hendrix H, Lindhout T, Mertens K, Engels W, Hemker HC. Activation of human prothrombin by stoichiometric levels of staphylocoagulase. J Biol Chem 1983; 258: 3637-44.

15. Hemker HC, Willems GM, Béguin S. A computer assisted method to obtain the prothrombin activation velocity in whole plasma independent of thrombin decay processes. Thromb Haemost 1986; 56: 9-17.

16. Hemker HC, Wielders S, Kessels H, Béguin S. Continuous registration of thrombin generation in plasma, its use for the determination of the thrombin potential. Thromb Haemost 1993; 70: 617-24.

17. Hemker HC, Giesen PL, Ramjee M, Wagenvoord R, Béguin S. The thrombogram: monitoring thrombin generation in platelet-rich plasma. Thromb Haemost 2000; 83: 589-91.

18. Wielders S, Mukherjee M, Michiels J, Rijkers DT, Cambus JP, Knebel RW, Kakkar V, Hemker HC, Béguin S. The routine determination of the endogenous thrombin potential, first results in different forms of hyper- and hypocoagulability. Thromb Haemost 1997; 77: 629-36.

19. Keularts IM, Zivelin A, Seligsohn U, Hemker HC, Béguin S. The role of factor XI in thrombin generation induced by low concentrations of tissue factor. Thromb Haemost 2001; 85: 1060-5.

20. Hemker HC, Béguin S. Phenotyping the clotting system. Thromb Haemost 2000; 84: 747-51.

21. Azar AJ, Koudstaal PJ, Wintzen AR, van Bergen PF, Jonker JJ, Deckers JW. Risk of stroke during long-term anticoagulant therapy in patients after myocardial infarction. Ann Neurol 1996; 39: 301-7.

22. Béguin S, Lindhout T, Hemker HC. The mode of action of heparin in plasma. Thromb Haemost 1988; 60: 457-62.

23. Butenas S, van't Veer C, Mann KG. "Normal" thrombin generation. Blood 1999; 94: 2169-78

Received December 11, 2001 Accepted after revision June 3, 2002 